As a token of gratitude and as a means to strengthen the initial relationship with Fellows, a one-year free subscription to Chemistry International will be provided to all Fellows during the first year following the cessation of active service. After one year, Fellows will be invited to subscribe to $\mathrm{Cl}$ directly through the Secretariat at a fee that will be set to cover anticipated costs to the Union.

An individual who is awarded Fellowship and later returns to active service in IUPAC for some period will receive a free subscription to $\mathrm{Cl}$ during the period of active service but will not receive another free year on cessation of the second period of service. Also, while individuals whose service to IUPAC concluded prior to the establishment of the Programme may become Fellows, they will not receive free subscriptions to $\mathrm{Cl}$.
All members of IUPAC bodies, Fellows and representatives of National Adhering Organizations, Observer Organizations and Associated Organizations whose e-mail addresses are known to the the Secretariat, should have received a broadcast e-mail message recently. If you did not receive this message, and would like to receive IUPAC news by email, please send your e-mail address and status (IUPAC body member, AMP member, etc.) to the secretariat: secretariat@iupac.org

\title{
World Science Conference
}

\section{This Conference is expected to be a major event relating Science to social concerns. Attendance will be by invitation only. The material below was distributed by ICSU and we believe it will be of interest to readers of Chemistry International.}

The 29th UNESCO General Conference last year adopted a resolution to organize a World Science Conference (WSC) in 1999. The Director General of UNESCO, Prof. F. Mayor, invited ICSU to cosponsor the WSC and the invitation was accepted by the ICSU Executive Board.

The Hungarian Government issued an invitation to host the Conference in Budapest from 26 June to 1 July 1999 and has offered very generous financial support. UNESCO and ICSU have accepted this kind invitation. The Hungarian Preparatory Committee has proposed a two centre arrangement for the Conference: the Budapest Convention Centre and facilities at the Hungarian Academy of Sciences.

The Conference is being co-organized by UNESCO and ICSU in co-operation with the relevant intergovernmental organizations of the United Nations system, and with nongovernmental organizations, such as the International Social Science Council (ISSC), the Third World Academy of Sciences (TWAS) and many other international and national partners.

ICSU will play a very important role in the 1999 World Science Conference. The Conference will address the entire phenomenon of science and its major issues at large, encompassing basic and applied science and facets relating to the natural and social sciences. The social and human sciences will be closely involved in addressing the social implications of overall scientific and technological progress, its particular breakthroughs, the relationship between science and development, as well as the ethical issues raised by the implementation of scientific research in specific areas. Emphasis will be laid on the increasing need for closer interaction and collaboration between both these realms of science throughout the themes discussed at the Conference.

The Conference aims to improve the public understanding of science and to obtain a renewed commitment of governments to fundamental and long-term research. The participants will be Government representatives, intergovernmental and nongovernmental organizations, policy makers, the scientific community and representatives of the public and other sectors of society.

The main outcome should be a world-wide innovative and pragmatic programme of action which will foster partnerships in science and the use of science for development and the environment. This programme, to be summarized in a 'Science Agenda-Strategy for Action', will be a framework for promoting co-operation and the coordination of efforts of governmental, intergovernmental, and nongovernmental bodies, the industrial sector and the scientific community. The ICSU will be responsible for the drafting of two scientific documents which will be the scientific input to the Agenda and the background documents for Forums I and II. The Agenda 
for Science in the XXIst Century will be drafted by UNESCO for Forum III.

The Conference will be organized around three fora, each dealing with a major umbrella topic. Each Forum will consist of a number of sessions and gatherings devoted to the topics of the programme. Suggestions for topics are listed below:

\section{Forum I: Science: its Achievements, Short- comings and Challenges}

- In-depth analysis of achievements of science (statistical approach: human longevity (The Biological Revolution) communication, transportation, etc.;

- Global Changes-achievements of international cooperation;

- Science and Industry: links between basic science, applied science and industrial development, role of foundations;

- The frontiers of science: prospective approach;

- Closing the gap between North and South;

- Sharing of scientific knowledge;

- Capacity Building and Education;

- Sustainability: Inter-Academy Panel.

\section{Forum II: Science and Society}

- Global problems of relations between Science and Society (including Science and Religion);

- Science, Environment and Society;

- Science and Media: how the media speaks of Science;

- Ethics and Responsibility of Scientists;

- Science and Industry: perception of science in industrial products: communication, transportation, food industry;

- Science and Peace;

- Science and Women.

\section{Forum III: Toward a New Commitment to Science}

- Commitment of scientists and nongovernmental scientific organizations;

- Commitment of intergovernmental scientific organizations;

- Commitment of civil society;

- Sustained political commitment;

- Commitment of industrial institutions and the private sector.

\section{Goals of the World Science Conference}

Through the World Science Conference, UNESCO's specific mandate in science will be exercised in order to draw up a guiding balance sheet of the main achieve- ments of science, its impact on society and development, the outcome of international scientific co-operation, as well as of the challenges for the next century, particularly those concerning the application of science to development, the rational use of natural resources and environment protection. Also, just as a world-wide political commitment to education for all has been achieved following the World Conference on Education for All (1990, Jomtien, Thailand), a renewed commitment to science by UNESCO's Member States, at both national and international levels, will be sought through an innovative and pragmatic plan of action that would pave the way to UNESCO's Medium-Term Strategy beyond the year 2000 .

The proposed World Science Conference will deal with the natural sciences and their impact on society. The social and human sciences will be closely involved in addressing the social implications of overall scientific and technological progress, its particular breakthroughs, the relationship between science and development, as well as the ethical issues raised by the implementation of scientific research in specific areas. Emphasis will be laid on the increasing need for closer interaction and collaboration between both these realms of science throughout the themes discussed at the World Science Conference.

The major objectives of WSC are to:

- undertake an in-depth analysis of the main achievements of science and its shortcomings; current problems and the forthcoming challenges in science with attention given to the role of science in the $21 \mathrm{st}$ century;

- contribute towards harmonizing the complex relations between science, society, development and environment, and promoting high ethical standards in scientific research and its applications, taking into consideration the specific cultural contexts of different regions;

- promote a world-wide endeavour geared towards the development of science, with particular attention to the needs of developing countries, and to enhance the interaction between scientists, public and private sectors and society;

- foster the renewal of international co-operation in the sharing of scientific knowledge in the age of information technologies, and give a new impetus to the development of science and its applications in the service of development, environmental protection, and the building of a culture of peace;

- engender the renovation of scientific education, particularly in the framework of 'education for all throughout life', and further improve the public understanding of science as part of culture through formal and informal processes and channels; and

- generate sustained political commitment to science 
by UNESCO's Member States and the main stakeholders of international co-operation, through an innovative and pragmatic plan of action beyond the year 2000 .

These objectives are to be met through a thoroughly conceived process encompassing the preparation of the Conference, the work of the Conference itself and its follow-up at national and international levels.

\section{Stakeholders and partners}

WSC will address and involve Member States' Governmental institutions, public and private sectors, scientists and nongovernmental bodies, as well as intergovernmental and international nongovernmental organizations involved in promoting and supporting science and scientific co-operation at regional and international levels. Particular attention will be given to involving women, youth and the media as partners and stakeholders of WSC.

Following wide consultations, the Director-General is of the view that the preferred status of the WSC would be that of a joint meeting of UNESCO and ICSU, organized in cooperation with the relevant intergovernmental organizations of the United Nations system, the International Social Science Council (ISSC), the Third World Academy of Sciences (TWAS) and other partners.

UNESCO, an intergovernmental body, and ICSU, a nongovernmental organization, have a unique mandate for, and authority in, promoting co-operation in science on the international stage, and they have been co-operating with each other for more than 50 years. Once the General Conference has endorsed WSC, co-operation will be officially sought with other interested bodies, namely, organizations of the United Nations system, intergovernmental organizations, international nongovernmental organizations and centres of excellence, financial institutions, major private foundations and regional and national scientific organizations. Preliminary contacts with the Organization for Economic Cooperation and Development (OECD), the World Bank, the International Association of Universities (IAU), the International Foundation for Science (IFS) and the Third World Academy of Sciences (TWAS) have indicated their wish to be involved in WSC.

\section{Format and topics}

The WSC will involve, in all its sessions, the participation and interaction of policy-makers, scientists and representatives of society. Efforts will be made to ensure that each Member State's delegation to the Conference will be composed of these three stakeholders. It is proposed that the sessions of WSC should revolve around the following three major umbrella topics:

- Science: its achievements, shortcomings and challenges;

- Interfaces of science;

- Towards a new commitment to science.

The first major topic aims to make the participants aware of the role of science and the responsibilities of the scientific community. The second topic seeks to involve focused discussions between scientists, governments, industrialists and representatives of the general public on the interfaces of scientific progress with societal requirements and expectations. The third topic follows logically, and aims to lead to an increased commitment to science by governments, policy-makers and other partners.

Each major topic will be dealt with in a limited number of sessions devoted to such issues or themes as: the history of science and its prospects for the future; science for economically viable, socially equitable and environmentally sound development; science and education, women's participation in science and technology; science and culture; ethical issues; commitment to science by governments and parliaments, scientists and intergovernmental and nongovernmental scientific organizations, etc. The elaboration of the key themes for the WSC working document will be selected by the Conference's scientific organizing committee, taking account of the recommendations made at the 29th session of the General Conference.

\section{Outcome and follow-up}

The main outcome of the WSC should be a world-wide innovative and pragmatic programme of action which will foster partnerships in science and the use of science for development and the environment. This programme, to be summarized in the document proposed to be entitled 'Science Agenda-Strategy for Action', will be a framework for promoting co-operation and the coordination of efforts of governmental, intergovernmental and nongovernmental bodies, the industrial sector and the scientific community. The draft document will be the subject of thorough consultations during the preparation of the Conference, before being discussed, finalized and endorsed by the Conference itself. A limited number of other documents, declarations and/or messages could be issued by the WSC as a goal-oriented framework for specific actions. By adopting and/or endorsing these documents, WSC will express the participants' determination to unite efforts and share responsibility for the promotion of science and its service to humankind.

WSC will also design an appropriate mechanism for overseeing its follow-up. The UNESCO Secretariat will be the focal body for co-ordinating this follow-up. In ad- 
dition, UNESCO's action in science and that of its scientific committees and intergovernmental programmes will be enhanced through the follow-up to WSC, as will UNESCO's cooperation with ICSU, and all other partners and stakeholders. It may be appropriate to announce at the Conference two or three world-wide initiatives for immediate follow-up, e.g. the setting up of international centres of excellence to promote sciencerelated activities such as science teaching and/or scientific research in certain regions.

\section{Preparatory work}

WSC will not follow the heavy and costly pattern of similar international conferences involving many regional and/or subregional preparatory meetings. It will, instead, take advantage of already planned regional meetings and small-scale international ad hoc meetings, involving natural and social scientists and policymakers, to help prepare the main working documents of WSC. The National Commissions of UNESCO and field offices will be involved in the preparatory process from the very beginning, as will be all the divisions of the Science Sector and intergovernmental programmes of both the Science Sector (IGCP, IHP, IOC, MAB) and the Sector of Social and Human Sciences (MOST) as well as pertinent units and programmes of other sectors of
UNESCO. Member States will be invited to designate national focal points for WSC in order to ensure their full participation in the preparatory work and the Conference itself. Use will be made of the new electronic communication technologies; a few forums through the Internet are envisaged to broaden consultations on the goals of the Conference and increase awareness of its usefulness.

Some meetings that may be conducive to WSC have already taken place (the International Conference on Donor Support to Development-Oriented Research in Basic Sciences, Sweden, June 1995; the Workshop on Basic Research for National Development Plans under Changing Economic Conditions, Slovenia, June 1997), or are under preparation (the Conference on Science and Technology Development in the Caribbean, Portof-Spain, September 1998; the meeting of the Genoa Forum on science and culture, and regional forums on science and women).

The third World Science Report and the first World Social Science Report will be circulated at WSC to provide background to the Conference thematic sessions. In addition to intersectoral consultation and partnership within UNESCO's Secretariat, preparatory activities for the World Conference on Higher Education (to be held in 1998) will be coordinated with those of WSC.

\section{News}

News from the Extraordinary Session of the ICSU General Assembly, 25 April 1998, Vienna, Austria

The Extraordinary General Assembly of ICSU was held to consider proposed changes to the organization of ICSU as a result of an Assessment Report made by a group of eminent scientists. Given below are excerpts from the Summary of Proposals provided the members before the meeting and excerpts from the revised Statutes adopted by the General Assembly.

\section{Recommendations for proposed action as a follow-up to the report on the assessment of ICSU}

\section{Introduction and summary of proposals}

\section{Introduction}

The recommendations contained in this document are proposed by the Executive Board of ICSU as a result of a wide consultation undertaken immediately following the 25th General Assembly. Specifically, the sources for this document are as follows.

- The recommendations in the Assessment Report (which itself was based on exhaustive consultations with ICSU family members).

- Responses from Members to the Assessment sent to Paris in April-May 1997.

- Recommendations of the January meeting of the Executive Board.

- Recommendations of the March meeting of the Standing Finance Committee.

- Recommendations of the March meeting of the Standing Committee on Membership, Structure and Statutes.

- Discussion by the Officers of ICSU in June.

\section{Summary of proposals}

(a) ICSU's name to be changed to better reflect the organization's aims and membership. 